\title{
The Role of Molecular Biology in Diagnosis and Follow-Up of Barrett's Esophagus
}

\author{
Karen Geboes and Anne Hoorens
}

Molecular pathways leading to the development of Barrett's esophagus (BE) and to the progression from Barrett's esophagus to esophageal adenocarcinoma (EAC) have been the focus of recent research. Surveillance of patients with BE relies on regular endoscopic surveillance to detect dysplasia and to diagnose carcinoma in an early treatable stage. Poor adherence to the recommended surveillance protocols with extensive sampling, as well as interobserver variability in evaluating dysplasia are, however, major drawbacks in this context, emphasizing the need for molecular biomarkers that may help in risk stratification of BE patients.

Definitions of BE vary between countries. In the USA, a diagnosis of Barrett's esophagus is only withheld when normal stratified squamous epithelium of the esophagus is replaced by an intestine-like columnar epithelium with goblet cells (specialized intestinal metaplasia), whereas in Japan and the United Kingdom BE is often used for any columnar mucosa found in the tubular esophagus.

There are different theories concerning the origin of BE and no consensus has been reached [1]. Multiple cell sources that may have undergone molecular reprogramming can be at the origin of BE. Transdifferentiation is a process in which one mature (differentiated) somatic cell type transforms directly into another type of mature somatic cell without undergoing an intermediate pluripotent state or progenitor cell type. It seems less probable that this is the origin of BE because it is unlikely that a nonproliferating differentiated squamous cell could sustain BE tissue indefinitely. Moreover, full phenotypic conversion of a cultured mature squamous cell has not yet been demonstrated. Transcommitment, in which undifferentiated

\footnotetext{
K. Geboes (西)

Department of Gastroenterology, Universitair Ziekenhuis Gent, Ghent, Belgium e-mail: karen.geboes@uzgent.be
}

\author{
A. Hoorens \\ Department of Pathology, Universitair Ziekenhuis Gent, Ghent, Belgium \\ e-mail: anne.hoorens@uzgent.be
}


progenitor cells in the esophagus that would normally differentiate into squamous cells instead differentiate into columnar cells, seems to be the more likely hypothesis.

Gene expression arrays showed that expression of genes of both gastric and intestinal epithelium can be found in Barrett epithelium. One hypothesis suggests an evolution from esophageal squamous epithelium to cardiac type glands and further into intestinal glands [2]. Another concept may be the evolution of Barrett glands from metaplasia of the stem cells of the proximal columnar gastric or cardiac epithelium [3]. In addition, circulating bone marrow-derived multi-potential stem cells have been shown to migrate to the esophagus and contribute to regeneration and metaplasia of esophageal epithelium following injury induced by irradiation or reflux $[4,5]$.

Whether its source are esophageal progenitor cells, residual embryonic cells at the squamo-columnar junction (SCJ), proximally shifting columnar progenitor cells from the gastric cardia, progenitor cells in the submucosal glands or ducts, circulating bone marrow-derived stem cells or esophageal differentiated squamous cells, the cells at the origin of BE would have to undergo molecular reprogramming with altered expression of key developmental transcription factors leading to a change in the cell's phenotypic committement [6]. Data exist to support each of these possible origins-progenitor cells in the esophagus, progenitor cells proximally shifting from the SCJ or cardia or progenitor cells circulating in the bloodstream, as a reaction upon injury - and none can be completely excluded. Esophageal squamous epithelial progenitor cells retain the embryonic capacity to switch between squamous and columnar phenotype, but must still undergo molecular reprogramming to give rise to specialized intestinal metaplasia. Pathways responsible for columnar differentiation, intestinalization, and mucus differentiation from epithelial cells with biphenotypic potential are described in the next paragraph.

\subsection{Development of BE and Dysplasia}

\subsubsection{Molecular Pathways Implicated in Development of BE}

The esophagus is derived from the embryological foregut. Four main signaling pathways in the differentiation of the embryological foregut have been identified thus far: the Bone morphogenetic protein (BMP), Hedgehog (HH), Wingless-Type MMTV Integration Site Family (WNT), and Retinoic acid (RA) signaling pathways (Fig. 10.1) [7]. It has been suggested that dysregulation of these embryological signaling pathways is involved in the development of BE.

Bone morphogenic proteins (BMPs) are members of the transforming growth factor- $\beta$ (TGFB) superfamily of ligands [8]. SHH (Sonic hedgehog) is one of the three ligands of the $\mathrm{HH}$ signaling pathway. The $\mathrm{SHH}$ protein is a secretory protein that regulates the expression of many genes, among which BMP genes. SHH-BMP cell signaling is essential for the development of many organ systems and their function is highly conserved between species. The three key transcription factors 


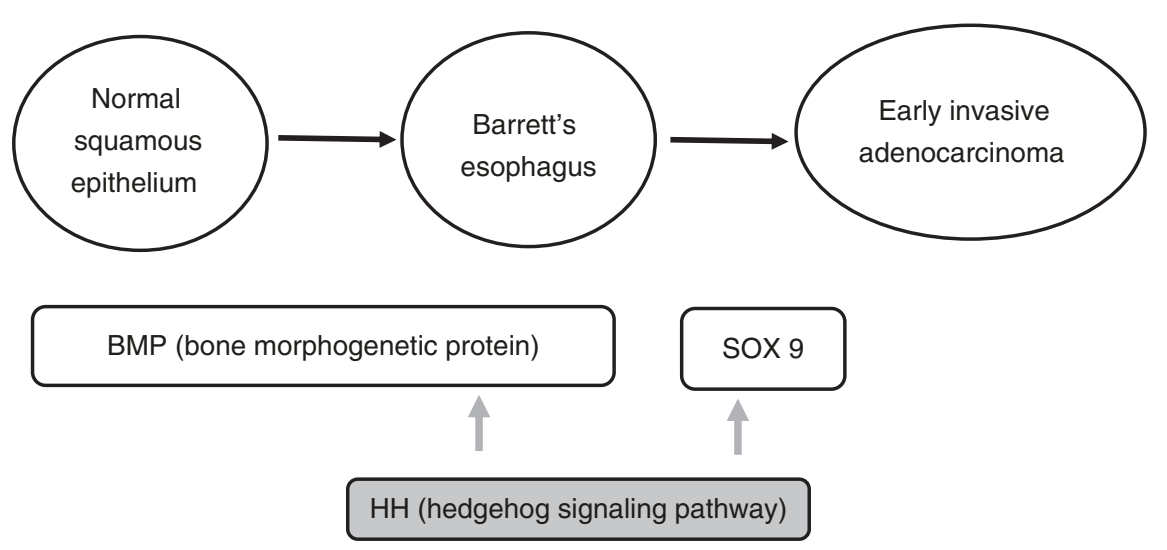

RA (retinoic acid signaling pathway)

WNT (wingless-type MMTV integration site family)

Fig. 10.1 Molecular pathways leading to the progression from normal squamous epithelium to Barrett's esophagus and adenocarcinoma

expressed by these pathways for the regulation of differentiation of foregut epithelium toward a squamous or columnar type are SOX2, p63, and NKX2.1. SOX2 and p63 induce squamous differentiation, while NKX2.1 expression is required for columnar differentiation [9].

Known risk factors for development of $\mathrm{BE}$ are chronic gastroesophageal reflux disease (GERD) and obesity. In normal squamous epithelium, the BMP pathway is not active [7]. In case of inflammation - as may be caused by GERD - the BMP pathway is activated with stromal BMP4 expression, contributing to a columnar transdifferentiation of squamous esophageal cells. In vitro studies showed that BMP4 induced a shift in the gene expression profile of squamous cells toward that of columnar cells, including an important shift of the cytokeratin (CK) expression pattern [10]. In BE, CK7 and CK20, markers for glandular differentiation, are highly expressed [11]. It is likely that $\mathrm{HH}$ signaling also contributes to BE development as expression of SHH was found to be increased in biopsies of $\mathrm{BE}$ and in a mouse model of BE [7]. The HH signaling pathway, as stated above, can activate BMP signaling. Furthermore, the HH pathway can also act by inducing epithelial SOX9 expression. SOX9 is a transcription factor of columnar-type genes, found to induce the expression of columnar-type cytokeratin 8 (CK8) in squamous cells, independent of BMP4 [12].

Where SHH and BMP4 are key players for the formation of a simple columnar epithelial lining, WNT as well as Notch signaling are subsequently implicated in the further differentiation of the intestinal mucosa into crypts and villi [13]. SOX9 protein is a WNT target expressed in the intestine, where it represses CDX2 and MUC2 
expression and may therefore contribute to the WNT-dependent maintenance of a progenitor cell phenotype [14]. CDX1 and CDX2 are homeobox genes playing a critical role in differentiation and maintenance of intestinal epithelial functions. CDX2 is normally not expressed in the normal esophagus, but nuclear CDX2 as well as CDX1 expression can be found in intestinal-type metaplasia [15]. CDX2 alone is insufficient to induce columnar metaplasia in squamous cells. CDX2 and MUC2 expression appear to be late events in columnar cells which already have an upregulated BMP4/pSMAD pathway and seem to be mediated by a pSMAD-CDX2 interaction, and in later stage WNT and Notch signaling [16, 17].

Activity of the retinoic acid (RA) signaling pathway is increased in the development of BE [7]. In incubation experiments, RA failed to induce complete columnar differentiation in a squamous cell line, but it did increase the expression of MUC2. During embryological development, in contrast, RA signaling contributes to squamous differentiation. These opposing effects might be related to differences in retinoid receptor subtype expression [7].

\subsubsection{Molecular Markers for the Diagnosis of BE}

Despite increasing knowledge of the molecular pathways leading to development of BE, no markers known to be specific for intestinal columnar epithelium, such as DAS1, CDX2, Hep Par 1, Villin, CK 7/20, or any of the MUC molecules (MUC2, MUCAC, MUC6), are helpful to distinguish between columnar epithelium of the distal esophagus and the proximal stomach [1]. Good communication between gastroenterologists and pathologists remains crucial in the identification of patients with short- or ultrashort-segment BE. Biopsies of the stomach may help in determining whether a biopsy with goblet cells in a patient suspicious for ultrashortsegment BE is indeed indicative of BE. Documentation of chronic gastritis with intestinal metaplasia (IM) in the stomach could indicate that the goblet cells in the biopsy may be secondary to diffuse chronic gastritis and not be due to BE.

\subsubsection{Markers for the Diagnosis of Dysplasia}

Several markers have been investigated, such as surface expression of cyclin A by immunohistochemistry, the proliferation marker Ki67, DNA content (aneuploidy/ tetraploidy), telomerase activity, genetic mutations (p53, p16, KRAS, APC, $\beta$-catenin), growth factors, apoptosis inhibitors, cyclooxygenase 2 , and alpha-methylacyl-CoA racemase (AMACR) immunohistochemistry [1, 18-20].

P53 is a transcription factor expressed from the tumor suppressor gene TP53. TP53 inactivation is the most common genetic alteration in dysplasia and early adenocarcinoma. Biallelic mutation of this gene will result in aberrant p53 immunohistochemical staining properties and in theory should provide an excellent diagnostic tool. Inactivating mutations of the p53 gene can be detected by immunohistochemistry, and this has been the most extensively studied marker in dysplasia in BE. The frequency of p53 mutation 
increases in BE neoplasia [21, 22]. However, studies investigating p53 immunohistochemistry suffered from high rates of both false positivity and false negativity and thus seemed not appropriate for the confirmation of a histologic diagnosis of dysplasia in patients with BE. The fact that studies failed to show unequivocal results may be due to different protocols and antibodies used. Recent data however, re-emphasize the value of p53 as an ancillary marker in BE. Quality assessment of p53 immunohistochemistry and recognition of complete absence of p53 staining as an indication of an inactivating mutation of the p53 gene, next to the more common pattern of $\mathrm{p} 53$ overexpression, may have contributed to better recognition of the value of p53 immunohistochemistry. If there is unequivocal dysplasia, p53 immunohistochemistry is not required. Dysplasia in BE in a minority of cases occurs without abnormal p53 staining and a definite morphological diagnosis of dysplasia should not be altered in case of normal p53 expression. P53 immunohistochemistry, however, appears to be a very useful marker in difficult cases as it improves the reproducibility of definite dysplasia in BE. Unfortunately, p53 is generally expressed aberrantly in both low- and high-grade dysplasia, so while appearing a very useful marker of dysplasia, its role in the grading of dysplasia is less clear [23].

The WNT signaling pathway is responsible for promoting the intestinal architecture. Activation of the WNT signaling pathway can be observed by overexpression of the WNT targets cyclin D1, SOX-9 and c-myc. WNT signaling appeared to play a role in progression to dysplasia, especially high-grade dysplasia [24].

Telomere shortening is correlated with cellular senescence and apoptosis. Cancer cells can escape apoptotic pathways by activating mechanisms involved in telomere elongation and stabilization. Telomerase is responsible for telomere maintenance. Inhibition of telomerase leads to shorter telomeres, reduced cell growth, and apoptosis. Higher telomerase activity may be an early event in maintaining genomic instability, even in the premalignant phase [25].

The frequency of AMACR-immunohistochemical positive staining increases in BE neoplasia [26, 27]. This enzyme is found in mitochondria and in peroxisomes. It has been described in low- and high-grade dysplasia, as well as in adenocarcinoma. Results of two studies were only moderately consistent in their findings [28].

\subsubsection{Genome-Wide Association Studies for the Development of Barrett's Esophagus}

There is a substantial overlap in the set of genes contributing to the risk of BE and adenocarcinoma of the esophagus. Genome-wide association studies have identified 8 loci within or near MHC, FOXF1, GDF7, TBX5, CRTC1, BARX1, FOXP1, and ALDH1A2 associated with the development of BE [29-31]. 


\subsection{Progression to Adenocarcinoma in $\mathrm{BE}$}

\subsubsection{Molecular Pathways Implicated in the Transition of Barrett's Esophagus to Early Adenocarcinoma}

Because BE is common in the population and only a minority of patients develop esophageal carcinoma, specific markers for the transition of BE to early adenocarcinoma are needed.

The signaling pathways implicated in the differentiation of the embryological foregut - the Bone morphogenetic protein (BMP), Hedgehog (HH), Wingless-Type MMTV Integration Site Family (WNT), and Retinoic acid (RA) signaling pathways - may be implicated in the progression from BE to EAC [7]. During the progression of BE toward malignancy, the SHH and WNT signaling pathways are upregulated while the RA and probably the BMP signaling pathways are downregulated. Further research however is required to further elucidate these issues since modulation of these pathways may be an option in the management of development of $\mathrm{EAC}$ in $\mathrm{BE}$.

\subsubsection{Molecular Biology of Progression to Adenocarcinoma}

C-myc and cyclins have been implicated as oncogenes, inducing hyperproliferation [32]. C-myc is a transcription factor essential for the expression of genes necessary for cell proliferation. The incidence of c-myc amplification was reported to increase with worsening histopathology [33]. Tumors with c-myc amplification in addition were found to show overexpression of COX2 and VEGF, genes involved in angiogenesis, a process essential for carcinoma development [34]. Cyclins have varying expression levels during cell cycle. Dysregulation of key players in the cell cycle can lead to tumor growth [32].

The mitogen-activated protein kinase (MAPK) RAS-RAF signaling pathway may be implicated in development of BE EAC. However, the phosphatidylinositol 3-kinase (PI3K) pathway has recently been identified by exome and whole-genome sequencing as the most frequently altered oncogenic pathway in esophageal adenocarcinoma development $[35,36]$. ErbB-2 mutations have been detected, but the role of erbB-2 (also called HER2/Neu) in the development of BE and EAC remains controversial [37]. The prevalence of HER2 amplification or overexpression has been reported to be high in BE and adenocarcinoma of the esophagus [38]. It was however also shown that the majority of HER2-amplified gastric as well as esophageal adenocarcinomas harbor secondary oncogenic alterations that can confer resistance to HER2-directed therapy [39]. HER2 and EGFR for example are frequently co-amplified and may dimerize with one another [39].

The TGF- $\beta$ signaling pathway regulating growth inhibition and suppression of genomic instability requires the transcription factors SMAD proteins and 
Runt-related transcription factor 3 (RUNX3). SMAD4 alterations may be stage specific and although BE and EAC share a common mutational landscape, SMAD4 mutations are confined to the malignant stage of the disease [40].

Inactivation of tumor suppressor genes p53, p16, p27, and APC has been implicated in the progression of BE to adenocarcinoma. Inactivation of p53 is thought to be a mechanism to avoid apoptosis of DNA damaged cells. Overexpression of cyclo-oxygenase- 2 , expression of NF- $\kappa \beta$, and downregulation of 15-lipoxygenase-1 have also been described, as well as expression of the anti-apoptotic proteins Bcl-2 and Bcl-XL and the pro-apoptotic protein Bax [41-43].

Aneuploid cells are at risk for neoplastic progression and in progression of BE to EAC epithelial cells were demonstrated to express aneuploidy [19].

Enhanced expression of both tumor necrosis factor receptor 1 (TNFR1) and TNF- $\alpha$, its ligand, has been described [44].

Epigenetic changes can lead to altered gene expression without the occurrence of mutations or structural variation. Hypermethylation of tumor suppressor genes such as APC, CDKN2A, CDH1, transcription factor ESR1 and REPRIMO-involved in the p53-mediated cell cycle arrest-has been demonstrated.

Small non-coding microRNAs (miRNAs) capable of degrading target mRNA via sequence complementarity have been the subject of many studies as well. miR-21 is one of the most expressed microRNAs in EAC [45]. miRNA-375 may be downregulated and is associated with c-myc and TP53 regulation [46]. Other frequently reported miRNAs are miR-192, -194, and -96A, that are more expressed with progression to malignancy, whereas miR-200 and miR-203 are downregulated [47]. miRNA could have unique expression profiles in different stages of malignant progression making them potential diagnostic indicators. miR-25, -99a, -133a, and $-133 \mathrm{~b}$ are purely diagnostic and miR-21, $-27 \mathrm{~b},-126,-143$, and-145 as a panel can be valuable both in diagnosis and prediction of progression [48].

\subsubsection{Molecular Markers for the Diagnosis of Progression to EAC}

Accumulation of aberrant chromosomal events resulting in aneuploidy, chromosomal rearrangements, tumor suppressor inactivation, and activation of oncogenes are associated with progression to carcinoma. Especially inactivation of the tumor suppressor gene p53, methylation markers, and DNA content (aneuploidy/tetraploidy) have been examined as potential markers to help to identify high-risk patients [18-21]. Aberrant p53 expression is associated with an increased risk of neoplasia, both overexpression and loss of expression [49]. In the overexpression pattern, an intense nuclear staining will be seen because of the accumulation of abnormal amounts of the p53 protein, due to mutations creating a protein product that is resistant to degradation. Complete lack of p53 labeling can be the result of homozygous deletion of the TP53 locus or can be caused by mutations in the TP53 transcript, accelerating its degradation. 


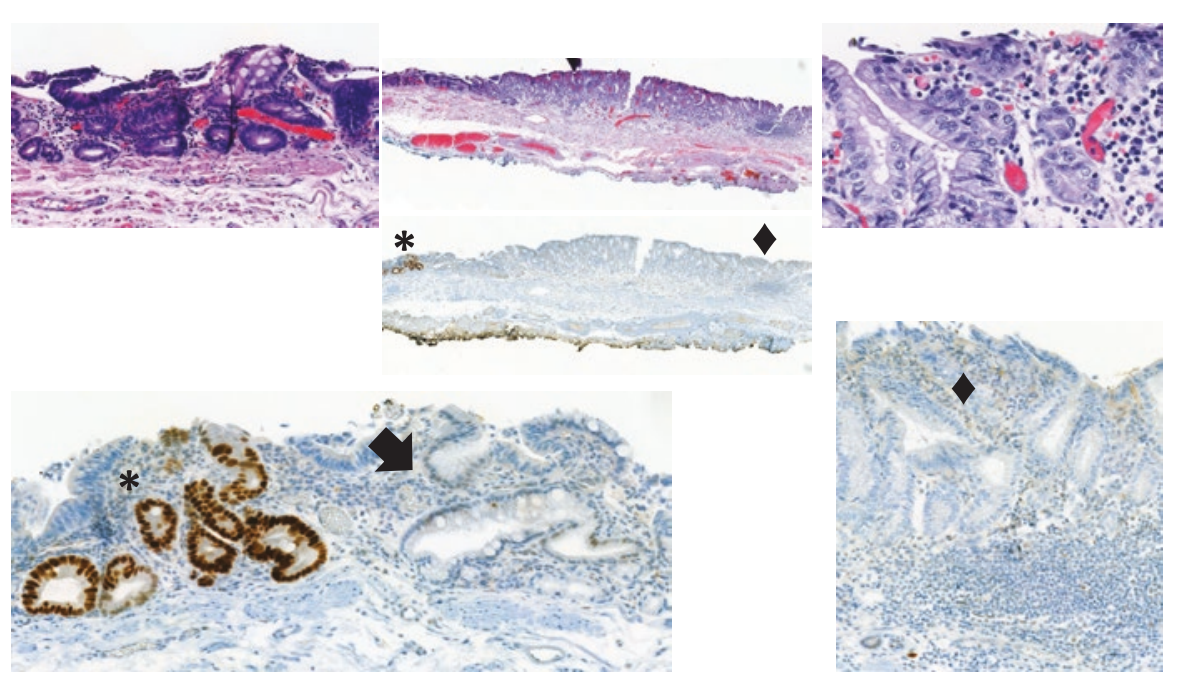

Fig. 10.2 Tissue section from an EMR (endoscopic mucosal resection) specimen-HE and p53 immunohistochemistry - with higher magnification of the regions indicated on the right (asterisk) and left (filled diamond) end. At the left end, there is an area of p53 overexpression (asterisk) corresponding with glands showing high-grade intestinal type dysplasia, while at the right end (filled diamond) we can observe an area of complete absence of p53 staining, corresponding in this case with glands showing foveolar type dysplasia. Next to the area of p53 overexpression, we recognize glands with intestinal metaplasia showing wild-type p53 expression (arrow)

Normal epithelium—both squamous and non-dysplastic columnar epitheliuminvariably express a low background amount of p53 protein because of ongoing DNA surveillance mechanisms, thus providing an internal p53 staining control. It is estimated that between 10 and $20 \%$ of BE with dysplasia show the so-called null mutation pattern with complete absence of staining. P53 function is altered or lost by mutation or loss of heterozygosity ( $\mathrm{LOH})$. Combination of biomarkers, such as DNA content and $\mathrm{LOH}$ of $\mathrm{p} 53$ and p16 appeared to be a good indicator of neoplastic progression [49-51]. Recent data show that aberrant expression of p53 in BE appears to be associated with a significantly increased risk of neoplastic progression also in non-dysplastic and low-grade dysplastic BE (Fig. 10.2).

\subsubsection{Genetic Changes Involved in the Progression From BE to EAC}

The concept that the evolution of cancer proceeds through a stepwise accumulation of genetic alterations in a predictable, linear manner has existed for a long time. It fits with phenotypic observations of changes in cell and structure, such as the progression from metaplastic BE over dysplastic BE to EAC. Consequently, for a long time, it was believed that specific genetic alterations would be present at different stages of neoplastic progression. 
Joint efforts such as The Cancer Genome Atlas and the International Cancer Gene Consortium helped us to understand somatic genetic and epigenetic alterations leading to the development of cancer by carrying out whole-genome and/or whole-exome sequencing in different cancer types.

These studies have demonstrated that there are more pathways to develop a malignancy by showing the heterogeneity of gene mutations that can occur in cancers in the population. We also learned that a tumor does not consist of one type of cancer cells, but that there is also intratumoral heterogeneity. With the exception of TP 53, few genes appear to be altered in a high number of cancer samples-and a large number of genes appear to be altered in only a minority of cases.

It remains hard to identify genetic changes responsible for driving certain events in the development of a specific cancer type. In BE associated EAC loci found near CRTC1, BARX1, FOXP1, and ALDH1A2 have been associated with development of both BE and esophageal adenocarcinoma [29-31]. These observations sustain a genetic component of $\mathrm{BE}$ and $\mathrm{EAC}$ associated with $\mathrm{BE}$.

The mutational load in esophageal adenocarcinoma is high and microsatellite instability is rare [52]. Despite a very high mutational load, very few genes were altered in more than $20 \%$ of cancers. The extensive copy number alterations and structural rearrangements found indicate a variety of mutational mechanisms active during progression to EAC. The small number of studies that examined BE around EAC found clonally related alterations in the precursor and the cancer, indicating that the evolution of somatic genomic alterations found in EAC begins in BE [52, 53].

\subsubsection{Biomarker Development}

Biomarkers with high specificity and sensitivity are needed for a reliable diagnosis of carcinoma in its earliest stage and for the identification of patients at risk. Most of the preclinical findings are not yet ready for clinical implementation.

As stated before, recent data show that aberrant expression of p53 in BE appears to be associated with a significantly increased risk of neoplastic progression also in non-dysplastic and low-grade dysplastic BE. If there is unequivocal dysplasia, p53 immunohistochemistry is not required. Dysplasia in BE in a minority of cases occurs without abnormal p53 staining and a definite morphological diagnosis of dysplasia should not be altered in case of normal p53 expression. P53 immunohistochemistry, however, appears to be a very useful marker in difficult cases, as aberrant expression in this context implies that these patients are at high risk of progression and should be managed as such. However, quality assurance of p53 immunohistochemistry is needed to improve staining method and interpretation. Also, further confirmation of these findings are needed, before this can be implemented in daily practice $[23,28]$.

Some other biomarker panels have been validated in large prospective cohorts. A set of methylation markers (p16, RUNX3, HPP1, NELL1, TAC1, SST, AKAP12, and CDH13) showed to have a good specificity, but low sensitivity [54]. A 
chromosomal abnormality panel can include TP53, CDNK2A (p16), LOH, and DNA content abnormality [55].

Attempts are made to combine molecular biomarkers with imaging techniques, in order to target biopsies more properly [56]. The cytosponge is an example of a tool developed to acquire reliable material in a minimally invasive way [57]. Coupled with immunohistochemistry for Trefoil Factor 3 it may identify patients with reflux symptoms who warrant endoscopy to diagnose BE. miRNA panels could be useful because the tissue-specific gene regulation may allow the development of a test based on a noninvasive blood collection [58].

None of these biomarker panels are ready for routine use. Studies evaluating reproducibility, specificity, and sensitivity are warranted. Biomarkers need to address the issues of under- and overdiagnosis and have to be validated for specific stages during progression to EAC.

\section{Conclusions}

Barrett's esophagus probably develops as a result of transcommitment, in which progenitor cells in the esophagus that normally would differentiate into squamous cells instead differentiate into columnar cells. The pathways responsible for columnar differentiation, intestinalization, and mucus differentiation from epithelial cells have largely been described. However, there are still many issues at the molecular level that need to be resolved in order to allow to develop novel molecular therapies.

Molecular markers for the diagnosis of dysplasia and early adenocarcinoma have been described, p53 being the most intensively studied. However, all markers suffer from high rates of both false positivity and negativity. Studies failed to show unequivocal results, possibly due to different protocols and antibodies used. More and more data confirm that aberrant expression of p53 in BE is associated with a significantly increased risk of neoplastic progression also in nondysplastic and low-grade dysplastic BE. Prospective validation studies are still warranted, even for the most promising markers, before they may be used as reliable biomarkers. Quality assurance of p53 immunohistochemistry is needed to improve staining method and interpretation, before this can be implemented in daily practice.

\section{References}

1. Naini BV, Souza RF, Otze RD. Barrett's esophagus: a comprehensive and contemporary review for pathologists. Am J Surg Pathol. 2016;40:e45-66.

2. Chandrasoma PT, Der R, Dalton P, et al. Distribution and significance of epithelial types in columnar-lined esophagus. Am J Surg Pathol. 2001;25:1188-93.

3. McDonald SAC, Lavery D, Wright NA, Jansen M. Barrett esophagus: lessons on its origins from the lesion itself. Nat Rev Gastroenterol Hepatol. 2015;12:50-60. 
4. Epperly MW, Guo H, Shen H, et al. Bone marrow origin of cells with capacity for homing and differentiation to esophageal squamous epithelium. Radiat Res. 2004;162:233-40.

5. Sarosi G, Brown G, Jaiswal K, et al. Bone marrow progenitor cells contribute to esophageal regeneration and metaplasia in a rat model of Barrett's esophagus. Dis Esophagus. 2008;21:43-50.

6. Wang D, Souza R. Transcommitment: paving the way to Barrett' metaplasia. In: Jansen M, Wright NA, editors. Stem cells, pre-neoplasia, and early cancer of the upper gastrointestinal tract. Advances in experimental medicine and biology 908. Basel: Springer; 2016. p. 183-212.

7. Pavlov K, Meijer C, van den Berg A, Peters FT, Kruyt FA, Kleibeuker JH. Embryological signaling pathways in Barrett's metaplasia development and malignant transformation; mechanisms and therapeutic opportunities. Crit Rev Oncol Hematol. 2014;92:25-37.

8. Fukuda K, Yasugi S. Versatile roles for sonic hedgehog in gut development. J Gastroenterol. 2002;37:239-46.

9. Litingtung Y, Lei L, Westphal H, et al. Sonic hedgehog is essential to foregut development. Nat Genet. 1998;20:58-61.

10. Milano F, van Baal JW, et al. Bone morphogenetic protein 4 expressed in esophagitis induces a columnar phenotype in esophageal squamous cells. Gastroenterology. 2007;132:2412-21.

11. El-Zimaity HMT, Graham DY. Cytokeratin subsets for distinguishing Barrett's esophagus from intestinal metaplasia in the cardia using endoscopic biopsy specimens. Am J Gastroenterol. 2001;96:1378-82.

12. Clemons NJ, Wang DH, Croagh D, et al. SOX9 drives columnar differentiation of esophageal squamous epithelium: a possible role in the pathogenesis of Barrett's esophagus. Am J Physiol Gastrointest Liver Physiol. 2012;303:G1335-46.

13. Elliott EN, Kaestner KH. Epigenetic regulation of the intestinal epithelium. Cell Mol Life Sci. 2015;72:4139-56.

14. Blache P, van de Wetering M, Duluc I, et al. SOX9 is an intestine crypt transcription factor, is regulated by the Wnt pathway and represses the CDX2 and MUC2 genes. J Cell Biol. 2004;166:37-47.

15. Guo RJ, Suh ER, Lynch JP. The role of Cdx proteins in intestinal development and cancer. Cancer Biol Ther. 2004;3:593-601.

16. Mari L, Milano F, Parikh K, et al. A pSMAD/CDX2 complex is essential for the intestinalization of epithelial metaplasia. Cell Rep. 2014;7:1197-210.

17. Krishnadath KK, Wang KK. Molecular pathogenesis of Barrett esophagus: current evidence. Gastroenterol Clin N Am. 2015;2:233-47.

18. Rioux-Leclercq N, Turlin B, Sutherland F, et al. Analysis of Ki-67, p53 and Bcl-2 expression in the dysplasia-carcinoma sequence of Barrett's esophagus. Oncol Rep. 1999;6:877-82.

19. Fritcher EG, Brankley SM, Kipp BR, et al. A comparison of conventional cytology, DNA ploidy analysis and fluorescence in situ hybridization for the detection of dysplasia and adenocarcinoma in patients with Barrett's esophagus. Hum Pathol. 2008;39:1128-35.

20. Younes M, Lebovitz R, Lechago L, et al. P53 protein accumulation in Barretts metaplasia, dysplasia and carcinoma: a follow-up study. Gastroenterology. 1993;105:1637-42.

21. Kaye PV, Haider SA, James PD, et al. Novel staining pattern of p53 in Barrett's dysplasia - the absent pattern. Histopathology. 2010;57:933-5.

22. Bhargava P, Eisen GM, Holterman DA, et al. Endoscopic mapping and surrogate markers for better surveillance in Barrett esophagus. A study of 700 biopsy specimens. Am J Clin Pathol. 2000;114:552-63.

23. Janmaat V, van Olphen S, Biermann K, et al. Use of immunohistochemical biomarker as independent predictor of neoplastic progression in Barrett's oesophagus surveillance: a systematic review and meta-analysis. PLoS One. 2017;12:e0186305. https://doi.org/10.1371/journal. pone. 0186305 .

24. Moyes LH, Mc Ewan H, Radulescu S, et al. Activation of Wnt signaling promotes development of dysplasia in Barrett's oesophagus. J Pathol. 2012;228:99-112. 
25. Lord RV, Salonga D, Danenberg KD, et al. Telomerase reverse transcriptase expression is increased early in the Barrett's metaplasia, dysplasia, adenocarcinoma sequence. J Gastrointest Surg. 2000;4:135-42.

26. Dorer R, Odze RD. AMACR immunostaining is useful in detecting dysplastic epithelium in Barrett's esophagus, ulcerative colitis and Crohn's disease. Am J Surg Pathol. 2006;30:871-7.

27. Scheil-Betram S, Lorenz D, Ell C, et al. Expression of alpha-methylacyl coenzyme A racemase in the dysplasia carcinoma sequence associated with Barrett's esophagus. Mod Pathol. 2008;21:961-7.

28. Kaye PV, Ilyas M, Soomro I, et al. Dysplasia in Barrett's oesophagus: p53 immunostaining is more reproducible than haematoxylin and eosin diagnosis and improves overall reliability, while grading is poorly reproducible. Histopathology. 2016;69:431-40.

29. Su Z, Gay LJ, Strange A, et al. Common variants at the MHC locus and at chromosome 16q24.1 predispose to Barrett's esophagus. Nat Genet. 2012;44:1131-6.

30. Palles C, Chegwidden L, Li X, et al. Polymorphisms near TBX5 and GDF7 are associated with increased risk for Barrett's esophagus. Gastroenterology. 2015;148:367-78.

31. Levine DM, Ek WE, Zhang R, et al. A genome-wide association study identifies new susceptibility loci for esophageal adenocarcinoma and Barrett's esophagus. Nat Genet. 2013;45:1487-93.

32. Souza RF, Spechler SJ. Concepts in the prevention of adenocarcinoma of the distal esophagus and proximal stomach. CA Cancer J Clin. 2005;55:334-51.

33. Sarbia M, Arjumand J, Wolter M, et al. Frequent c-myc amplification in high-grade dysplasia and adenocarcinoma in Barrett esophagus. Am J Clin Pathol. 2001;115:835-40.

34. von Rahden BH, Stein HJ, Pühringer-Oppermann F, Sarbia M. c-myc amplification is frequent in esophageal adenocarcinoma and correlated with the upregulation of VEGF-A expression. Neoplasia. 2006;8:702-7.

35. Sommerer F, Vieth M, Markwarth A, et al. Mutations of BRAF and KRAS2 in the development of Barrett' adenocarcinoma. Oncogene. 2004;23:554-8.

36. Dulak AM, Stojanov P, Peng S, et al. Exome and whole-genome sequencing of esophageal adenocarcinoma identifies recurrent driver events and mutational complexity. Nat Genet. 2013;45:478-86.

37. Gowryshankar A, Nagaraja V, Eslick GD. HER2 status in Barrett's esophagus and esophageal cancer: a meta analysis. J Gastrointest Oncol. 2014;5:25-35.

38. Langer R, Rauser S, Feith M, Nährig JM, et al. Assessment of ErbB2 (Her 2) in oesophageal adenocarcinomas: summary of a revised immunohistochemical evaluation system: bright field double in situ hybridization and fluorescence in situ hybridization. Mod Pathol. 2011;24:908-16.

39. Kim J, Fox C, Peng S, et al. Preexisting oncogenic events impact trastuzumab sensitivity in ERBB2-amplified gastro-esophageal adenocarcinoma. J Clin Invest. 2014;124:5145-58.

40. Weaver JM, Ross-Innes CS, Shannon N, et al. Ordering of mutations in preinvasive disease stages of esophageal carcinogenesis. Nat Genet. 2014;46:837-43.

41. Wilson KT, Fu S, Ramanujam KS, et al. Increased expression of inducible nitric oxide synthase and cyclooxygenase-2 in Barrett's esophagus and associated adenocarcinomas. Cancer Res. 1998;58:2929-34.

42. Shureiqi I, Xu X, Chen D, et al. Nonsteroidal anti-inflammatory drugs induce apoptosis in esophageal cancer cells by restoring 15-lipoxygenase-1 expression. Cancer Res. 2001;61:4879-84.

43. Katada N, Hinder RA, Smyrk TC, et al. Apoptosis is inhibited early in the dysplasia-carcinoma sequence of Barrett esophagus. Arch Surg. 1997;132:728-33.

44. Tselepis C, Perry I, Dawson C, et al. Tumour necrosis factor-alpha in Barrett's oesophagus: a potential novel mechanism of action. Oncogene. 2002;21:6071-60081.

45. Feber A, Xi L, Luketich JD, et al. MicroRNA expression profiles of esophageal cancer. J Thorac Cardiovasc Surg. 2008;135:255-60.

46. Garman KS, Owzar K, Hauser ER, et al. MicroRNA expression differentiates squamous epithelium from Barrett's esophagus and esophageal cancer. Dig Dis Sci. 2013;58:3178-88. 
47. Revilla-Nuin B, Parilla P, Lozano JJ, et al. Predictive value of MicroRNAs in the progression of Barrett esophagus to adenocarcinoma in a long-term follow-up study. Ann Surg. 2013;257:886-93.

48. Sakai NS, Samia-Aly E, Barbera M, Fitzgerald RC. A review in the current understanding and clinical utility of miRNAs in esophageal cancer. Semin Cancer Biol. 2013;23:512-21.

49. Kastelein F, Biermann K, Steyerberg EW, et al. Aberrant p53 protein expression is associated with an increased risk of neoplastic progression in patients with Barrett's oesophagus. Gut. 2013;62:1676-83.

50. Bird-Lieberman EL, Dunn JM, Coleman HG, et al. Population-based study reveals new riskstratification biomarker panel for Barrett's esophagus. Gastroenterology. 2012;143:927-35.

51. Wang JS, Guo M, Montgomery EA, et al. DNA promoter hypermethylation of p16 and APC predicts neoplastic progression in Barrett's esophagus. Am J Gastroenterol. 2009;104:2153-60.

52. Agrawal N, Jiao Y, Bettegowda C, et al. Comparative genomic analysis of esophageal adenocarcinoma and squamous cell carcinoma. Cancer Discov. 2012;2:899-905.

53. Streppel MM, Lata S, DelaBastide M, et al. Next-generation sequencing of endoscopic biopsies identifies ARID1A as a tumor suppressor gene in Barrett's esophagus. Oncogene. 2014;33:347-57.

54. Jin Z, Cheng Y, Gu W, et al. A multicenter, double blinded validation study of methylation biomarkers for progression prediction in Barrett's esophagus. Cancer Res. 2009;69:4112-5.

55. Galipeau PC, Li X, Blount PL, et al. NSAIDs modulate CDNK2A, TP53 and DNA content risk for progression to esophageal adenocarcinoma. PLoS Med. 2007;4:e67. https://doi. org/10.1371/journal.pmed.0040067.

56. Di Pietro M, Boerwinkel DF, Shariff MK, et al. The combination of autofluorescence endoscopy and molecular biomarkers is a novel diagnostic tool for dysplasia in Barrett's oesophagus. Gut. 2015;64:49-65.

57. Ross-Innes CS, Debiram-Beecham I, O’Donovan M, et al. BEST2 Study Group. Evaluation of a minimally invasive cell sampling device coupled with assessment of trefoil factor 3 expression for diagnosing Barrett's esophagus: a multi-center case control study. PLoS Med. 2015;12:e1001780. https://doi.org/10.1371/journal.pmed.1001780.

58. Bansal A, Lee IH, Hong X, et al. Discovery and validation of Barrett's esophagus microRNA transcriptome by next generation sequencing. PLoS One. 2013;8:e54240. https://doi. org/10.1371/journal.pone54240. 